\title{
Contribuição dos assentamentos rurais no desmatamento da Amazônia: um olhar sobre o Estado do Pará
}

\section{Contribution of Rural Settlements in Amazon Deforestation: a Look at the State of Pará}

\author{
Danielle CALANDINO* \\ Magda WEHRMANN** \\ Rodrigo KOBLITZ ${ }^{* * *}$
}

\begin{abstract}
RESUMO
A colonização de terras devolutas na região amazônica para fins de reforma agrária, política social que vem sendo priorizada pelo governo em detrimento de uma política efetiva de redistribuição de terras - o que não foge substancialmente do padrão histórico de ocupação dirigida da região -, tem causado consequências socioambientais em diversas áreas do desenvolvimento que necessitam ser mais intensamente exploradas. Com o intuito de subsidiar essa discussão sob o prisma ambiental, recorreu-se à análise de geoprocessamento. Como medida de impacto ambiental, foi avaliada a dinâmica do desmatamento em 15\% dos assentamentos federais do Estado do Pará, durante cinco anos. Os resultados demonstraram haver proporcionalmente mais desmatamentos no interior dos assentamentos do que na área que os circunscreve. No entanto, a velocidade de incremento do desmatamento ao longo dos anos é menor dentro dos assentamentos, quando se excluem as áreas protegidas do Estado. O estudo aponta para possíveis causas que contribuem para a tendência de desmatamento no âmbito dos assentamentos. Fatores como a vulnerabilidade econômica, o atraso na liberação dos financiamentos rurais, as incertezas fundiárias, tamanho dos lotes e a exploração madeireira em assentamentos fictícios são apontados como algumas das causas determinantes do padrão observado.
\end{abstract}

Palavras-chave: assentamentos; desmatamento; Amazônia, Pará.

\begin{abstract}
The colonization of land in the Amazon region for purposes of agrarian reform, promoted by the government as a social policy throughout history rather than a policy of land redistribution, has caused environmental consequences in various areas of development that need to be further explored. In order to support this argument through the environmental prism, we used the GIS analysis. As a measure of
\end{abstract}

\footnotetext{
"Mestra em Ciências Biológicas (Botânica) - UFRJ. Doutoranda em Desenvolvimento Sustentável pela Universidade de Brasília (UnB). E-mail: dcalandino@gmail.com "** Doutora em Sociologia (UnB). Professora do Centro de Desenvolvimento Sustentável da Universidade de Brasília (UnB). E-mail: mwehrmann@hotmail.com

*** Mestre em Ecologia (UERJ). Analista Ambiental da Diretoria de Licenciamento Ambiental do Instituto Brasileiro do Meio Ambiente e dos Recursos Naturais Renováveis (DILIC/IBAMA). E-mail: rodrigokoblitz@yahoo.com.br
} 
environmental impact, it was assessed the deforestation dynamics in $15 \%$ of federal settlements in the state of Pará for five years. The results showed proportionally more deforestation inside the settlements than in the restricted area. However, the rate of increase in deforestation over the years is lower within the settlements, if we exclude the areas protected by the state. The study points to possible causes that contribute to the trend of deforestation within the settlements. Factors such as economic vulnerability, the delay in the release of rural financing, land uncertainties, size of lots and logging in fictitious settlements, some are appointed as determinants of the observed pattern.

Keywords: settlements; deforestation; Amazon; Pará.

\section{Introdução}

Desde o início da colonização do Brasil, a fronteira agrícola brasileira tem sido deslocada para o interior, à procura de terras férteis e baratas (UICN et al., 2011), com a prerrogativa principal de proteção do território e garantia da soberania nacional. Esse padrão induzido, produzido e exaustivamente reforçado e estimulado pelas políticas públicas de incentivo à ocupação da Amazônia desde o Governo Vargas foi intensificado durante a ditadura militar, sob o pretexto de "integrar para não entregar". Como resultado, observa-se uma política mais colonizadora do que reformista, consolidada com a mínima interferência nos interesses do setor privado. Assim, os esforços de reforma agrária na Amazônia Legal têm sido conduzidos com a abertura de novas áreas de ocupação, a partir da colonização de terras públicas que não acarretam uma mudança na estrutura fundiária do país (PASQUIS et al., 2005; FAGGIN, 2009, TOURNEAU; BURSZTYN, 2010).

Em decorrência deste modelo, a demografia da região amazônica é fortemente influenciada por um grande fluxo migratório de famílias entre regiões geográficas, com diferentes peculiaridades, exigências ecológicas e padrões socioeconômicos. Com menos de $15 \%$ da população rural do país, ela abriga quase $55 \%$ dos lotes distribuídos pelo Instituto Nacional de Colonização e Reforma Agrária - INCRA (TOURNEAU; BURSZTYN, 2010).

Como consequência, resultam colonizações por trabalhadores rurais dotados de saberes que pouco correspondem à realidade econômica e ambiental amazônica e que pouco contribuem para um bom aproveitamento do solo em suas múltiplas dimensões. Considerando que, tradicionalmente, a conversão dos habitats nativos em usos alternativos tem sido a forma de apropriação do território brasileiro (UICN et al., 2011), as condições acima aumentam enormemente as chances de esse modelo reforçar o desmatamento e a degradação ambiental na região.

Diversos estudos têm sido desenvolvidos para verificar o desmatamento acarretado por projetos de assentamento da reforma agrária na região amazônica, sobretudo após o Ministério do Meio Ambiente (MMA) anunciar em 2008 que os projetos de assentamento do INCRA figuravam dentre as seis primeiras posições na lista dos responsáveis pelo desmatamento da Amazônia. Segundo Brandão Jr. e Souza Jr. (2006), até 2004 15\% do desmatamento registrado na Amazônia ocorreu no interior de assentamentos da reforma agrária.

Com o objetivo de contribuir com a discussão sobre os impactos ambientais dos assentamentos rurais na Amazônia, esse estudo apoiou-se em estimativas das taxas de desmatamento a partir da análise de geoprocessamento de $15 \%$ dos assentamentos federais do Estado do Pará.

O Estado foi escolhido para o estudo por apresentar mais de $30 \%$ de sua área coberta por assentamentos - o maior em área de assentamentos (BRANDÃO Jr.; SOUZA Jr., 2006). Ao mesmo tempo, o Pará tem historicamente figurado entre a lista dos Estados que mais desmatam no país, conforme informações oficiais disponibilizadas no site do Instituto Nacional de Pesquisas Espaciais (INPE).

Após avaliar quantitativamente a dinâmica do desflorestamento, discorremos sobre alguns fatores que potencialmente a configuram. 


\section{Metodologia}

A evolução do desmatamento no interior dos assentamentos federais do Estado do Pará foi acompanhada a partir de técnicas de análise em geoprocessamento, durante um período de cinco anos - 2006 a 2010 -, de acordo com a metodologia descrita a seguir.

Os shapes de desmatamento, assentamentos e áreas protegidas do Estado do Pará foram sobrepostos no software ArcGis. A área de interseção de três diferentes conjuntos de análise, denominados cenários, foi calculada de acordo com os critérios descritos na seção 2.3.

\section{1. Área de estudo}

Dos 670 assentamentos rurais federais identificados pela Secretaria de Estado de Projetos Estratégicos do Estado do Pará (SEPE), foram selecionados aqueles com data de criação posterior a 2006 (Figura 1). Isto resultou em 99 assentamentos, o equivalente a $15 \%$ do total de assentamentos federais atuais, localizados no Estado do Pará, independente de sua modalidade.

A amostragem, embora relativamente pequena, contempla mais de $60 \%$ das famílias beneficiadas pela reforma agrária no Estado (Tabela 1).

TABELA 1 - CARACTERÍSTICAS GERAIS DOS ASSENTAMENTOS DO ESTADO DO PARÁ E NA ÁREA AMOSTRADA

\begin{tabular}{l|c|c|c|c|c|c}
\hline \multirow{2}{*}{ Amostra } & \multicolumn{2}{|c|}{ Número } & \multicolumn{2}{c|}{ Famílias } & \multicolumn{2}{c}{ Área (ha) } \\
\cline { 2 - 7 } & $\mathrm{n}$ & $\%$ & $\mathrm{~N}$ & $\%$ & $\mathrm{n}$ & $\%$ \\
\hline Estado do Pará & 670 & 100 & 51.825 & 100 & $10.744 .335,86$ & 100 \\
\hline $\begin{array}{l}\text { Assentamentos } \\
\text { selecionados } \\
\text { para o estudo } \\
\text { (recorte } \\
\text { amostral) }\end{array}$ & 99 & 15 & 32.289 & 62 & $3.371 .379,05$ & 31 \\
\hline
\end{tabular}

\subsection{Levantamento das informações espaciais}

Os dados espaciais de desmatamento do Estado do Pará, localização geográfica dos assentamentos e APs, obtidos a partir das fontes descritas na Tabela 2, foram sobrepostos utilizando o software ArcGis 9.X (Figura 2).
TABELA 2 - FONTES DOS DADOS ESPACIAIS

\begin{tabular}{l|l}
\hline Shape & Fonte \\
\hline $\begin{array}{l}\text { Assentamentos do } \\
\text { INCRA }\end{array}$ & $\begin{array}{l}\text { Secretaria de Estado de Projetos Estraté- } \\
\text { gicos do Estado do Pará - SEPE (http:// } \\
\text { www.sepe.pa.gov.br/zee/index.asp) }\end{array}$ \\
\hline Unidades de & $\begin{array}{l}\text { Centro de Sensoriamento Remoto do Ins- } \\
\text { tituto Brasileiro do Meio Ambiente e dos } \\
\text { conservação (UCs) } \\
\text { e Terras Indígenas (TIs) }\end{array}$ \\
$\begin{array}{l}\text { Recursos Naturais Renováveis - CSR/ } \\
\text { IBAMA (http://siscom.ibama.gov.br/si- } \\
\text { tecsr/) }\end{array}$ \\
\hline $\begin{array}{l}\text { Polígonos de desmatamento do Programa } \\
\text { de Cálculo do Desflorestamento da Ama- } \\
\text { zônia do Instituto Nacional de Pesquisas } \\
\text { Espaciais - PRODES/INPE (http://www. } \\
\text { dpi.inpe.br/prodesdigital/prodesuc.php) }\end{array}$ \\
\hline
\end{tabular}

\subsection{Cálculo da área desmatada}

Foi computada a área desmatada entre os anos de 2006 e 2010 para três diferentes cenários, a saber:

\section{a. Cenário Assentamentos}

Contempla o desmatamento no interior dos assentamentos selecionados.

Foi obtida pelo cálculo da área de interseção entre polígonos de desmatamento do PRODES para os anos de 2006 a 2010 e assentamentos criados antes do ano de 2006 (Figura 2), considerando inclusive as áreas de preservação permanente ou reservas legais sob seu domínio.

\section{b. Cenário Fora dos assentamentos (FA)}

Corresponde ao desmatamento externo aos assentamentos, considerando todo o Estado do Pará, incluindo as áreas protegidas (APs) - aqui consideradas somente as unidades de conservação e terras indígenas.

\section{c. Cenário Fora dos assentamentos rurais sem APs (FA sem APs)}

Desmatamento externo aos assentamentos, considerando todo o Estado do Pará, excetuando-se as unidades de conservação e terras indígenas.

Este terceiro cenário foi construído para que o resultado da avaliação do desmatamento na área externa aos assentamentos não fosse suavizado por áreas e condições especiais de proteção especial. 


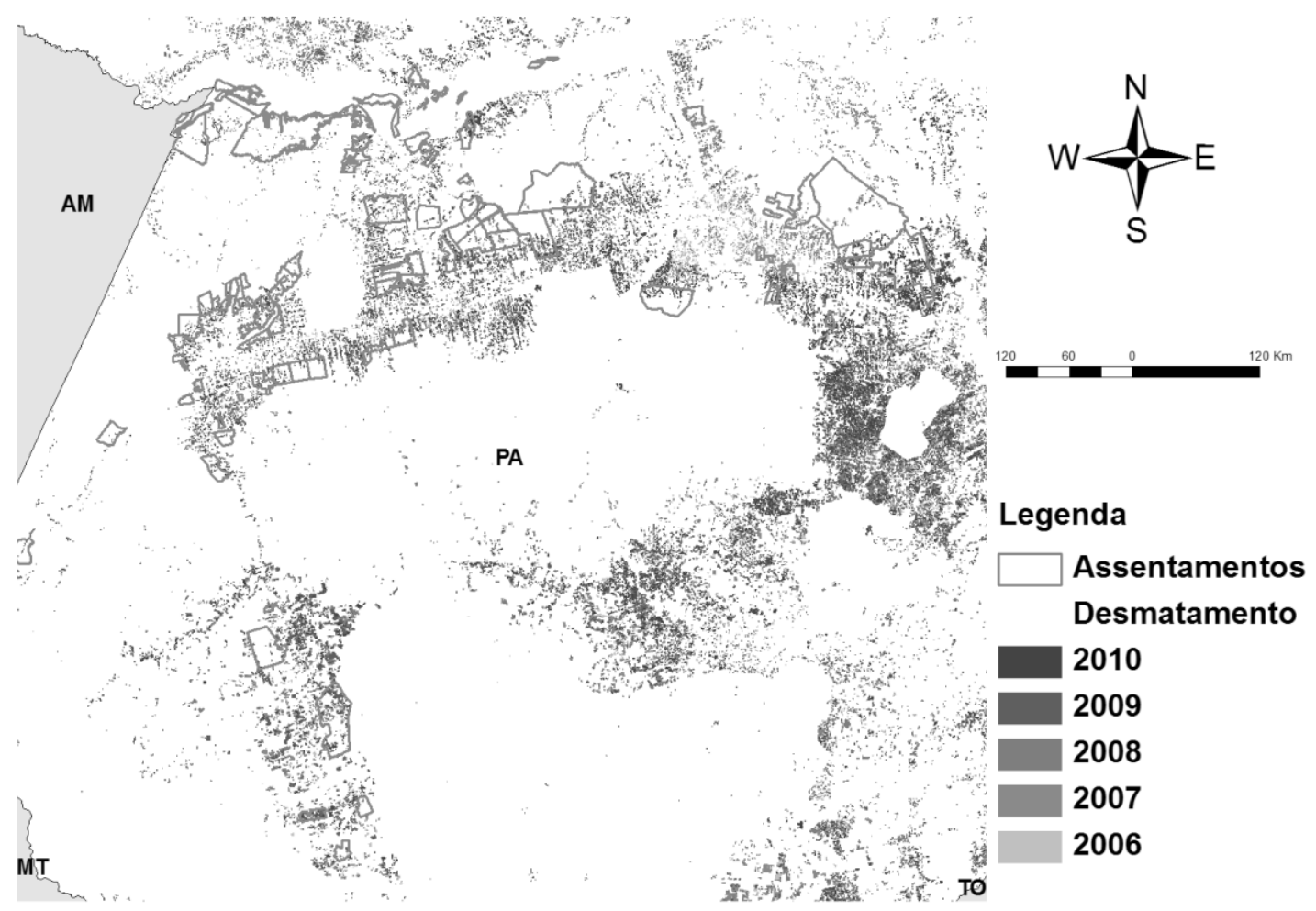

FIGURA 1 - Assentamentos estudados e o desmatamento nos anos de 2006 e 2010 no Estado do Pará. FONTE: PRODES/INPE e SEPE/PA. Autoria própria, julho de 2011.
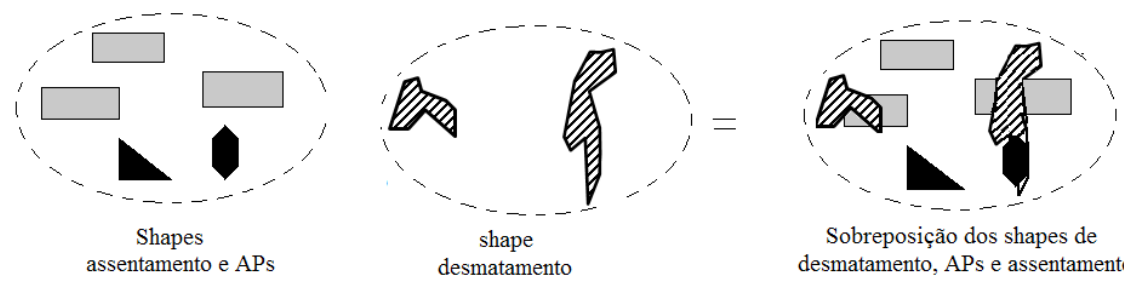

Sobreposição dos shapes de desmatamento, APs e assentamentos

\section{LEGENDA}
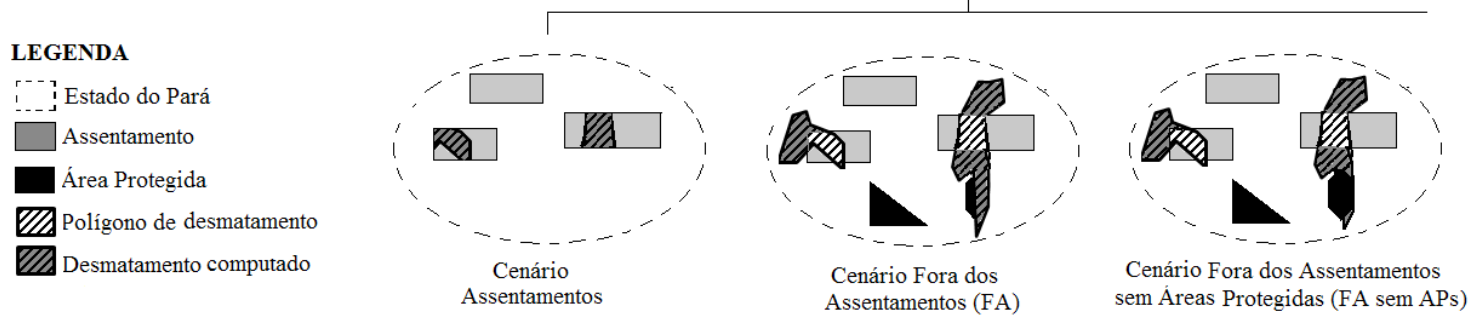

FIGURA 2 - Esquema ilustrativo da metodologia de quantificação do desmatamento nos três cenários de desmatamento estudados. 


\section{Resultados e discussão}

\subsection{Desmatamento acumulado}

O estudo da dinâmica do desmatamento nos três cenários durante cinco anos demonstrou haver proporcionalmente um maior percentual de áreas desmatadas no interior dos assentamentos, quando comparado ao desmatamento externo, em ambos os cenários (Tabela 3).

Como se esperava, as áreas protegidas amenizam a tendência de desmatamento fora dos assentamentos, de forma que as excluindo da análise (cenário FA sem APs), o percentual desmatado sofre incremento.

Diversos estudos encontraram resultado semelhante ao comparar o desmatamento em assentamentos com outras destinações de uso dentro de uma mesma região da Amazônia legal (BARRETO et al., 2008; BRANDÃO Jr.; SOUZA Jr., 2006).

TABELA 3 - DESMATAMENTO NOS TRÊS CENÁRIOS AVALIADOS

\begin{tabular}{l|r|r|c}
\hline $\begin{array}{l}\text { Categoria de } \\
\text { análise }\end{array}$ & Área total (ha) & $\begin{array}{c}\text { Desmatamento } \\
\text { acumulado de } \\
\mathbf{2 0 0 6 - 2 0 1 0} \text { (ha) }\end{array}$ & $\begin{array}{c}\text { \%o } \\
\text { desmatado } \\
\text { entre } \\
\mathbf{2 0 0 6 - 2 0 1 0}\end{array}$ \\
\hline Assentamentos & $3.371 .379,05$ & $111.924,82$ & 3,32 \\
\hline FA total & $124.768 .950,00$ & $2.478 .300,00$ & 1,99 \\
\hline FA sem APs & $56.146 .027,50$ & $1.480 .778,31$ & 2,64 \\
\hline
\end{tabular}

LEGENDA: FA total - Fora dos assentamentos contabilizando as áreas protegidas; FA sem APs - Fora dos assentamentos descontando APs.

\subsection{Taxa média anual de desmatamento}

Uma maior taxa de desmatamento foi encontrada dentro dos assentamentos, como observado também por Brandão Jr. e Souza Jr. (2006) ao avaliar 343 assentamentos do Instituto Nacional de Colonização e Reforma Agrária (INCRA) criados na Amazônia, de 1970 a 2002.

No entanto, a despeito de responder proporcionalmente por uma maior área desmatada, os assentamentos possuem taxas médias anuais de desmatamento menores do que o desmatamento fora dessas áreas, quando se exclui da análise as áreas sob regime especial de proteção (Figura 3). Ou seja, os assentamentos apresentam um índice de desmatamento menor do que o território que o circunscreve.

As causas responsáveis pelos padrões encontrados são muitas e nem sempre perceptíveis a partir de avaliações indiretas, tais como a técnica de acompanhamento remoto utilizada nesta análise. Na prática, a dinâmica socioeconômica se expressa também a partir de ações não verificáveis pelos canais oficiais de monitoramento, a partir de soluções desenvolvidas pela sociedade para preenchimento de lacunas impermeáveis à implementação das atuais políticas públicas, que aos poucos se tornam a própria justificativa de novas políticas.

Esses interstícios, dificilmente captados pelos métodos analíticos indiretos, os tornam instrumentos limitados ao entendimento de interações mais complexas. No entanto, a simplificação do real, propiciada pelas ferramentas de geoprocessamento, possibilita interpre-

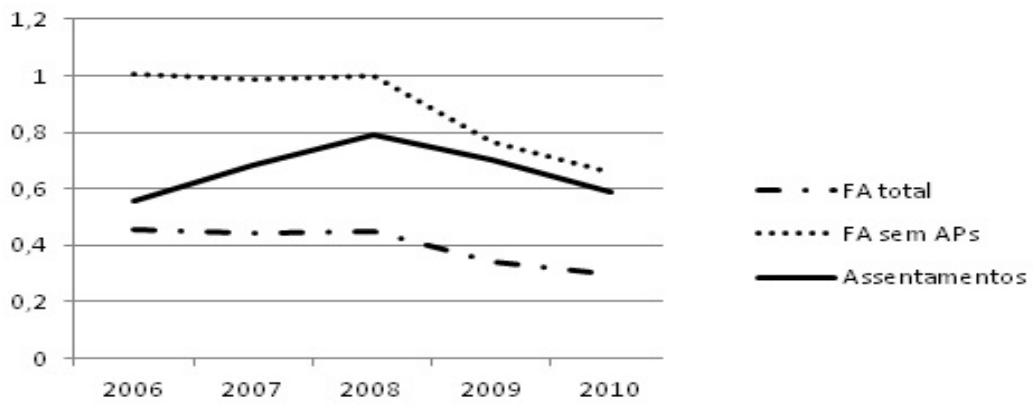

FIGURA 3 - Comparação entre as taxas médias anuais de desmatamento nos três cenários avaliados.

LEGENDA: FA total - Fora dos assentamentos contabilizando as áreas protegidas; FA sem APs - Fora dos assentamentos descontando APs. Fonte: PRODES/INPE e SEPE/PA. 
tações muito aproximadas, sobretudo em associação com análises e interpretações mais baseadas em métodos qualitativos.

Assim, entendendo as limitações do método analítico indireto e sem a intenção de esgotar o assunto ou atribuir juízo de valor à política de assentamentos, serão discorridos, a seguir, alguns fatores que potencializam o desmatamento naquelas áreas.

\subsection{Fatores que contribuem com a dinâmica do desmatamento em assentamentos rurais}

\section{a. Pressão externa de desmatamento}

Ao comparar as Figuras 3 e 4, percebe-se que a tendência de inversão das taxas de desmatamento nos três cenários a partir de 2008 é retrato de uma tendência geral para toda a Amazônia. O resultado demonstra que os assentamentos rurais, embora apresentem uma lógica socioeconômica diferente da agricultura patronal e dos outros modos de produção capitalista, respondem ao contexto socioeconômico ao qual se inserem, mantendo seus laços integradores com a sociedade englobante, tal como considerou Wanderley (2009), ao avaliar a agricultura familiar.
Além da influência da dinâmica de desflorestamento que os circunscreve, algumas causas inerentes ao modelo de reforma agrária devem ser consideradas, tais como as enunciadas na sequência.

\section{b. Vulnerabilidade econômica dos assentados}

A grande dificuldade de acesso a financiamentos rurais subsidiados pelo governo tem sido relatada em uma expressiva proporção de projetos. O atraso na liberação dos recursos compromete significativamente a agricultura, pois os recursos não chegam no momento do ciclo agrícola em que são mais necessários (LEITE et al., 2007). Com frequência, consegue-se o acesso ao benefício apenas com intervenção política, apesar das garantias institucionais dadas aos agricultores, pois na prática não há recurso governamental para todos (NAASE, 2010).

Sem recursos, mínima infraestrutura e com alto grau de isolamento físico de outros povoados, os assentados rurais se deparam com uma situação de grande vulnerabilidade socioeconômica. Condição fortemente agravada pela falta de identidade sociocultural (isolamento cultural) com a terra em que vivem, em decorrência do deslocamento de sua terra natal (Figura 4), imposto pela atual política de reforma agrária.

$\mathrm{Km} 2$

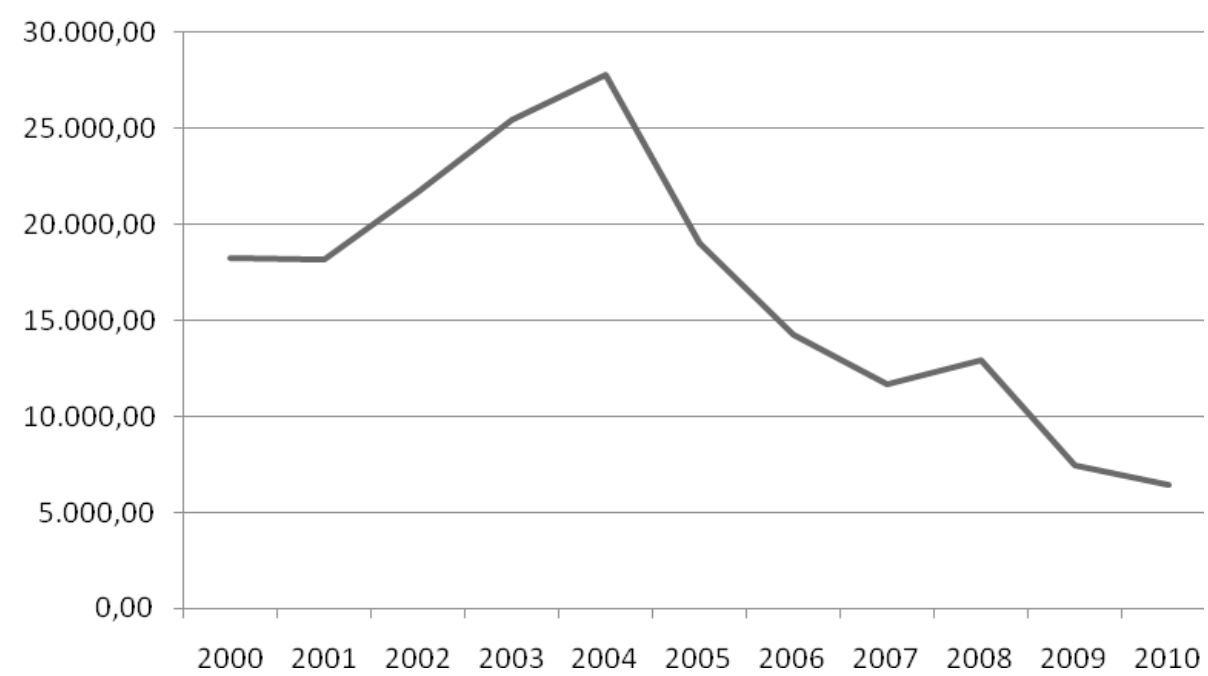

FIGURA 4 - Série histórica de desmatamento na Amazônia legal. FONTE: INPE. 


\section{FAMILIAS EM OCUPAÇÕES E FAMÍLIAS ASSENTADAS - 1988-2006}

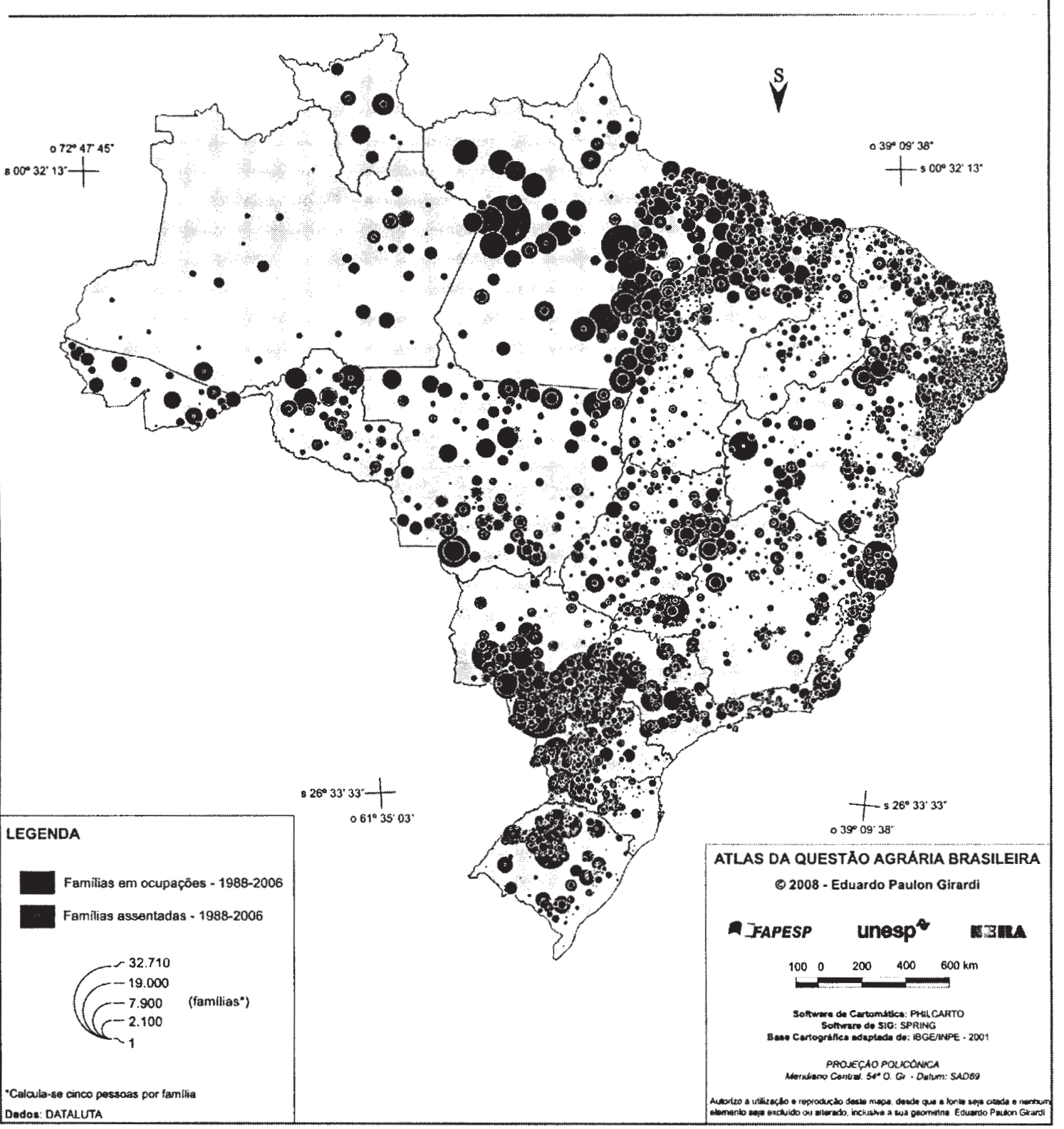

FIGURA 5 - Localização das famílias em ocupações e em assentamentos ilustrando onde se localizam as demandas e onde são localizadas as ofertas de terras para reforma agrária.

FONTE: GIRARDI, Eduardo P. Atlas da Questão Agrária Brasileira. São Paulo: Unesp, 2008. 
Sem conseguir investir em sua produção, os assentados frequentemente exploram o que têm de maior liquidez e com a maior abundância: a madeira.

Naase (2010) destaca o quão paradoxal é essa condição: beneficiários da reforma agrária desmatam justamente por apresentar as características solicitadas dos beneficiários da reforma agrária, expressada na sua vulnerabilidade socioeconômica. Em outras palavras, a política de assentamento seleciona famílias de grande fragilidade socioeconômica, mas como a mesma política de assentamento é ineficiente em criar condições socioeconômicas propícias à instalação das famílias, elas acabam se apoiando em soluções de rápido retorno financeiro, como a exploração madeireira ou a venda de lotes.

Valendo-se dessa fragilidade, muitas madeireiras abastecem o mercado a partir da exploração de madeira em assentamentos, em troca da abertura de estradas e escolas, mesmo antes delas terem licenciamento ambiental ou plano de manejo florestal aprovado (GREENPEACE, 2007).

A falta de conscientização ambiental restringe o entendimento dos pequenos agricultores, que consideram as áreas de uso restrito dos assentamentos (áreas de proteção permanente e reservas legais) áreas sem importância econômica, um obstáculo ao desenvolvimento. As madeiras mais valiosas são então vendidas aos madeireiros por preços irrisórios, deixando uma floresta empobrecida em variedade de espécies e com sua função ambiental comprometida (WOLSTEIN et al., 1998).

\section{c. Demora na definição da titularidade da terra}

Cunha e Nunes (2008) defendem que os conflitos motivados pela exploração dos recursos naturais em assentamentos, particularmente aqueles de uso comum, não resultam da falta de uma consciência ambiental por parte dos assentados nem simplesmente da precariedade de suas condições de vida, que os forçam a explorar intensivamente alguns recursos para garantir a sobrevivência de suas famílias, mas estão vinculados à incerteza dos direitos de propriedade existentes naquele momento.
A demora extraordinária na transferência dos títulos dos lotes para os assentados gera incertezas que favorecem a "tragédia dos bens comuns", ${ }^{1}$ intensificando a exploração de recursos naturais em situações de livre acesso (CUNHA; NUNES, 2008; NAASE, 2010).

\section{d. Tamanho dos lotes}

O pequeno tamanho dos lotes nos assentamentos tem sido apontado como um importante obstáculo à consolidação de uma agricultura familiar produtiva sustentável e/ou em conformidade com a legislação ambiental em lotes de pequeno tamanho (NAASE, 2010; TOURNEAU; BURSZTYN, 2010). Estabelecer um sistema que garanta a preservação de reservas legais e áreas de preservação permanente, conciliando gado e sistemas agrícolas de pousio, não é possível em lotes de tamanho reduzido.

Guanziroli et al. (2001) citam como exemplo o tradicional sistema roça + coivara da região Norte do Brasil, cuja sustentabilidade exige uma rotação longa para permitir a recomposição da floresta e a incorporação de matéria orgânica produzida pelas capoeiras. O encurtamento do tempo de coivara, em razão da escassez de terra, produz degradação ambiental, decadência e inviabilidade deste sistema de produção.

Além disso, a divisão de terras em parcelas reduzidas, por si só, gera desmatamento em função do efeito de borda. ${ }^{2}$ Isto ocorre porque a fragmentação de um habitat aumenta drasticamente a quantidade de margens, criando diferentes microambientes na borda do fragmento e no interior da floresta, gerando uma área de transição abrupta entre a floresta e o habitat ao redor. Como consequência imediata da fragmentação, destaca-se a redução da área do habitat disponível (FERRAZ, 2011).

Becker (2007) propõe a formação de fazendas solidárias para contornar as dificuldades de se estabelecer uma agricultura sustentável. Trata-se de grandes fazendas formadas pelo somatório da área de cada assentado, que funcionam como cooperativas e são dotadas de uma única e grande reserva florestal coletiva, o que, para fins de manutenção das funções ecossistêmicas, pode também

\footnotetext{
${ }^{1}$ Teoria de Garret Hardin (1968), na qual o livre uso acarretaria, via de regra, a superexploração e a degradação do meio ambiente.

${ }^{2}$ Alteração na estrutura, na composição e/ou na abundância relativa de espécies na parte marginal de um fragmento.
} 
representar uma excelente saída por permitir uma maior conectividade de ambientes.

$\mathrm{Na}$ literatura encontram-se outros defensores das reservas legais coletivas como uma solução para se evitar o parcelamento do solo e a maior exposição de animais (WOLSTEIN et al., 1998, dentre outros).

\section{e. Modelo de assentamento}

Embora este estudo não tenha feito distinção entre os tipos de assentamentos, provavelmente os resultados sofrem maior influência dos projetos de assentamentos clássicos, ${ }^{3}$ já que eles respondem por $72 \%$ dos assentamentos da região amazônica (TOURNEAU; BURSZTYN, 2010).

Sendo assim, deve ser observada a dinâmica do desmatamento em outros tipos de assentamentos, como o caso daqueles onde há incorporação de práticas agroecológicas.

De acordo com Theodoro et al. (2009), além dessas práticas resultarem em maior conservação da qualidade ambiental, podem representar importantes estratégias para a conquista de uma maior autonomia da produção agrícola do país e, portanto, maior soberania. Isso porque a política agrícola convencional torna o país extremamente dependente das importações de fertilizantes e outros insumos químicos oriundos de um pequeno grupo de grandes empresas.

No entanto, a realidade é indutora de mudanças para padrões de exploração menos sustentáveis. Para Guanziroli et al. (2001), a combinação de recursos disponíveis como terra, mão de obra familiar, capital e tecnologia, bem como a luta pela sobrevivência, podem determinar a utilização de sistemas pouco sustentáveis no médio e longo prazos.

\section{f. Assentamentos de papel}

Em 2007, o Greenpeace divulgou um relatório-denúncia sobre o esquema firmado entre madeireiras da região de Santarém e o INCRA. Segundo a organização não governamental (ONG), muitos assentamentos não possuíam sequer assentados e foram criados apenas para justificar a exploração madeireira.

\subsection{Caminhos possíveis}

As deficiências no sistema de gestão do território que acirram os conflitos entre as políticas ambientais e agrárias poderiam ser corrigidas ou mitigadas a partir de algumas medidas:

- reforma agrária a partir de terras particulares já alteradas;

- priorização de alocação dos projetos com maior proximidade dos centros urbanos e/ou com infraestrutura que favoreça o escoamento da produção;

- assistência técnica adequada à realidade local;

- recuperação de áreas desmatadas nos assentamentos, especialmente aquelas situadas nas áreas de Reserva Legal e Áreas de Preservação Permanente (BRANDÃO Jr.; SOUZA Jr., 2006);

- promoção de políticas de reintegração sociocultural para maior aproveitamento da biodiversidade local nas áreas de assentamento;

- necessidade de tornar o setor agrícola verdadeiramente eficiente, superando sua tradição extensiva e desperdiçadora de terras;

- fornecer incentivos financeiros e fiscais às atividades com base na conservação da floresta e/ ou sua utilização sustentável;

- inclusão dos assentamentos no programa federal de monitoramento do desmatamento na Amazônia (BRANDÃO Jr.; SOUZA Jr., 2006).

\section{Conclusões}

Os resultados encontrados são importantes para evidenciar a contribuição quantitativa dos assentamentos no desmatamento amazônico. No entanto, são pouco indicativos das causas socioeconômicas relacionadas ao padrão encontrado.

Uma análise descuidada poderia conduzir a questão para a discussão do modelo de exploração que vem sendo desenvolvido pela agricultura familiar e sobre a sustentabilidade desse modelo do ponto de vista ambiental. No entanto, antes de condenar a estratégia, é fundamental

\footnotetext{
${ }^{3}$ Categoria onde os autores agrupam antigos Projetos Integrados de Colonização (PIC), os Projetos de Assentamento Dirigidos (PAD), os Projetos de Assentamento
} Rápido (PAR) e os atuais Projetos de Assentamento (PAs). 
considerar que, muitas vezes, os beneficiários não fazem parte do público-alvo definido pelo Governo Federal. $\mathrm{Ou}$ seja, é evidente a descaracterização social dos verdadeiros beneficiados pela reforma agrária.

A incerteza fundiária e o atraso na concessão de crédito e de infraestrutura mínima representam fortes

\section{Referências}

BARRETO, P.; PEREIRA, R.; ARIMA, E. A pecuária e o desmatamento na Amazônia na era das mudanças climáticas. Belém: Instituto do Homem e do Meio Ambiente da Amazônia, 2008.

BECKER, B. Primeiras intervenções. In: NASCIMENTO, E. P.; VIANNA, J. N. Dilemas e desafios do desenvolvimento sustentável no Brasil. Rio de Janeiro: Garamond, 2007.

BRANDÃO Jr., A.; SOUZA Jr., C. Deforestation in land reform settlements in the Amazon. State of the Amazon, Belém, n. 7, p. 1-4, 2006.

CUNHA, L. H.; NUNES, A. M. B. Proteção da natureza e conflitos ambientais em assentamentos rurais. Desenvolvimento e Meio Ambiente, Curitiba: Editora UFPR, n. 18, p. 27-38, 2008.

FAGGIN, J. M. Reforma agrária, sustentabilidade e participação: o caso do Projeto de Desenvolvimento Sustentável São Luiz, Cajamar-SP. Dissertação (Mestrado em Desenvolvimento Sustentável) - UnB. Brasília, 2009.

FERRAZ, A. C. P. Efeitos de borda em florestas tropicais sobre artrópodes, com ênfase nos dípteros ciclorrafos. Oecologia Australis, v. 15, n. 42, p. 189-198, 2011.

GREENPEACE. Assentamentos de papel, madeira de lei: relatório-denúncia. Relatório-denúncia - Parceria entre Incra e madeireiros ameaça a Amazônia. 2007. Disponível em: $<\mathrm{http} / /$ www.greenpeace.org/brasil/pt/Documentos/greenpeacebr_070821_amazonia_relatorio_assentamentos_incra_port_v2/>. Acesso em: fev. 2012.

GUANZIROLI, C.; ROMEIRO, A.; BUAINAIN, A. Di S.; BITTENCOURT, G. Agricultura familiar e reforma agrária no século XXI. Rio de Janeiro: Garamond, 2001.

LEITE, S. P.; HEREDIA, B.; MEDEIROS, L.; PALMEIRA, M.; CINTRÃO, R. Impactos econômicos dos assentamentos ameaças à sustentabilidade dos assentamentos. Esta dependência de variáveis reforça a importância de se implementar políticas integradas de desenvolvimento territorial, sem as quais não será possível conciliar crescimento econômico com cidadania e qualidade ambiental.

rurais no Brasil: análise das suas dimensões regionais. Revista Economia Ensaios, v. 22, n. 1, p. 1-21, 2007.

NAASE, K. M. Recursos naturais, espaço social e estratégias de vida em assentamentos da reforma agrária na Amazônia brasileira (Sudeste Paraense). Bol. Mus. Paraense Emílio Goeldi. Cienc. Hum., v. 5, n. 1, p. 79-102, 2010.

PASQUIS, R.; SILVA, A. V.; WEISS, J. MACHADO, L. Reforma agrária na Amazônia: balanço e perspectivas. Cadernos de Ciência \& Tecnologia, Brasília, v. 22, n. 1, p. 83-96, 2005.

THEODORO, S. H.; DUARTE, L. G.; ROCHA, E. L. Incorporação dos princípios agroecológicos pela extensão rural brasileira: um caminho possível para alcançar o desenvolvimento sustentável. In: ; VIANA, J. N. (Orgs.). Agroecologia: um novo caminho para a extensão rural sustentável. Rio de Janeiro: Garamond, 2009.

TOURNEAU, F. M.; BURSZTYN, M. Assentamentos rurais na Amazônia: contradições entre a política agrária e a política ambiental. Ambiente e Sociedade, v. 8, n. 1, p. 111-130, 2010.

UICN; WWF-BRASIL; IPÊ. In: WEIGAND Jr., R.; CALANDINO, D.; OLIVEIRA E SILVA, D. (Orgs.). Metas de Aichi: situação atual no Brasil. Brasília: Ministério do Meio Ambiente, 2011.

WANDERLEY, M. N. B. O mundo rural como um espaço de vida: reflexões sobre a propriedade da terra, agricultura familiar e ruralidade. Porto Alegre: Editora da UFRGS, 2009.

WOLSTEIN, A. R. P.; LIMA, E. M.; AMARAL, E. F. do; BRAZ, E. M.; PINHEIRO, F. L. N.; FRANKE, I. L.; SANTOS, M. H. dos; SILVA, R. F. Metodologia para o planejamento, implantação e monitoramento de projetos de assentamentos sustentáveis na Amazônia. Rio Branco: Embrapa, 1998.

Recebido em 29 de fevereiro de 2012. Aceito em 23 de julho de 2012. Publicado em dezembro de 2012. 